\title{
Enhance Risks Management of Software Development Projects in Concurrent Multi-Projects Environment to Optimize Resources Allocation Decisions
}

\author{
Ibraheem M Alharbi ${ }^{1}$, Adel A Alyoubi ${ }^{2}$, Majid Altuwairiqi ${ }^{3}$, Mahmoud Abd Ellatif ${ }^{4}$ \\ College of Business, University of Jeddah, $\mathrm{SA}^{1,2,4}$ \\ College of Computer and IT, Taif University, $\mathrm{SA}^{3}$ \\ Faculty of Computers and AI, Helwan University, Egypt ${ }^{4}$
}

\begin{abstract}
In software development project management, Risk management represents critical knowledge and skills at the level of a single software project and at the enterprise level, which executes multiple software projects concurrently. The best decision of Risk management contributes to optimizing resource allocation at the enterprise level for achieving its goals. Therefore, the issue needs centralized risk management at the enterprise level as a whole and not for each project. Risk management is implemented through several stages and using different methods. Various studies deal with multiple aspects of software management. This research provides an analytical view of risk assessment in multi-environment software development projects that take place simultaneously. The study uses a public dataset previously used in previous research for several simultaneous projects in one organization. It describes the multisoftware project's risks through 12 variables. A comparative analysis uses classification methods (Random Forest- TreesJ48 REP Tree - Simple Logistic) to assess risks and put them in central view. The research experiment has proven high accuracy in determining risk levels in a multi-project environment, reaching approximately $98 \%$, using the REP tree technique.
\end{abstract}

Keywords-Risk management; multiple software projects; risk assessment; software development projects

\section{INTRODUCTION}

The study, analysis, and management of software project risks remain essential in research and practice, despite all the attempts to provide solutions. Still, the reports monitor high failure rates in software development projects. Risk Management (RM) is one of the critical tasks facing project managers. The importance of risk management is due to labor laws and legislation as well as industry standards and internal guidelines for enterprises. The first principle of RM according to ISO 31000 standard is that "RM creates and protects value" [14].

The Standish Group Report presented a comparative analysis on projects from 2013 until the end of 2017. In this period, the three-class of project results (success, challenge, and failure) are illustrated in Fig. 1 [33]. It displays the differences between waterfall and agile. It assures that an agile project succeeds approximately $2 \mathrm{X}$ more than a waterfall and
1/3 less likely to fail. According to the Standish Group, 2018 Chaos Reports, an agile project has a $60 \%$ bigger success rate than waterfall projects. The main idea learned is that all software development projects face risks regardless of the development methodology.

Therefore, IEC 31010:2019 guides the selection and application of risk assessment techniques in a wide range of situations. Many standards focus on how to manage the activities of risk management in IT organizations. These standards illustrate how to address risks in organizations and companies. Various ISO standards target management systems such as quality perspectives in ISO 9001, IT Service Management (ITSM) in ISO/IEC 20000 - 1, project management in ISO 21500, and information security in ISO/IEC 27001. These IT - related and non - IT standards are significant for many companies [6].

Risk assessment and forecasting in the early stage of softw are project development is essential for risk management and $\mathrm{i}$ mproved success rate of software development projects. There fore, organizations must assess and analyze the risks of softwa re projects to be planned by more accurately identifying potent ial risks and adopting scientific risk mitigation methods. Softw are risk factors may be diverse and complex, and historical data may be uncertain and unregulated [19].

The International Organization for Standardization (ISO) has issued a standard risk management framework [14]. The main objective of ISO 31000 is to support enterprises in managing risk. ISO 31000 displays the principles, framework, and process of Risk Management. An organization can use it regardless of its level of size, activity, or sector. The definition of risk assessment in ISO 31000 consists of three subprocesses: identifying risk, analyzing risk, and evaluating risk. The sub-process identifying risk is used to determine, recognize, and define the affected risks on the project's objectives. The main aim of analyzing risk is to know the nature, causes, and sources of the identified risks for evaluation risk level. Evaluating risk aims to determine the acceptable level of risk and what should be tolerated, based on comparing risk analysis results with risk criteria [29] [14]. 


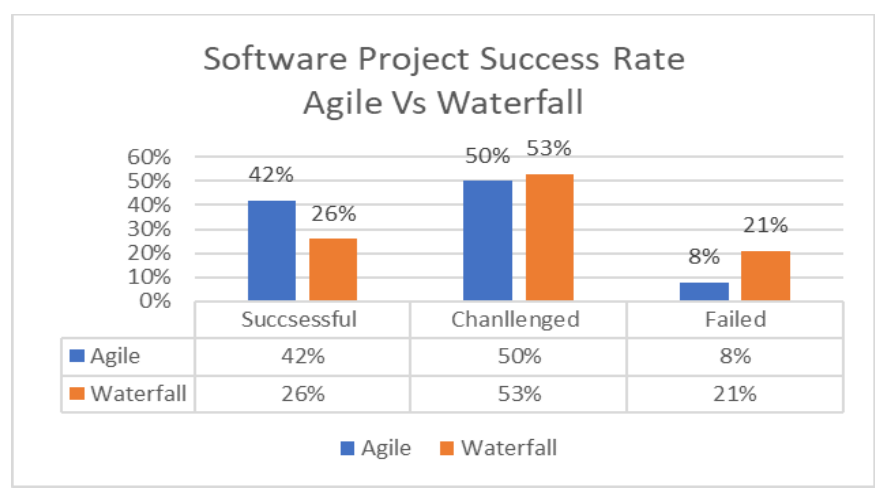

Fig. 1. Projects Success Rates (Adapted from [33]).

In NASA, enhance the safety decision process by using a Probabilistic Risk Assessment (PRA) methodology. It identifies Risks through the answer of three basic questions: the first is What can go wrong? , the second is, How likely is it? And the third is What are the consequences? These answers are prepared by systematically identifying, model, and quantify scenarios. These answers may be lead to knowing an undesired result. Qualitative and risk assessment requires quantitative semantic models. In addition, the probability theory is very descriptive and does not fit the calculation [37].

A simultaneous multi projects development environment is the common environment in software companies. Whereas rarely, software development company executes one project within the timeframe. However, various software projects are developed within the same time frame. Some of these projects consider developing government service portals, e-commerce portals, point-of-sale software, management information system software, enterprise resource planning systems, or other types of different software projects with various characteristics and features. So, the various projects are developed concurrently, and they are concurrent and sharing resources. Therefore, the management of the software development company needs to be concerned with each project restriction - scope, cost, schedule, quality, and relationships among these projects. In short, the main objective of project management, at the company level, should be expanded to improve resource allocation within the entire organization environment, not focus on each project individually.

Based on the previous paragraph, risk management in a multi-project environment has become more complex. Managers face difficult decisions on reducing the average delay per project or the time needed to complete the full range of projects using effectively allocated resources [16]. Risk management in the simultaneous software development environment will be more complex by the diversity of methodologies, policies, models, and procedures in the development process. Dealing with risk management in a single project is very different from a multi-project environment simultaneously. However, many IT organizations do not give much importance to risk management. Risk management is still subjective and often not uniform and does not take place with a systematic methodology.
Companies may need to adopt a centralized risk management methodology that helps maintain their market share through optimal resource management. They may lose if there is no proactive risk management. A supportive regulatory structure is also needed to achieve the central management of risky institutions to control risks throughout the organization.

The main objective of this paper is to clarify the relationships between the risk features and the level of risk and how risks are classified and assessed in simultaneous multiple software development projects. Therefore, this research tries to answer the following questions:

1) What are the relationships between risk level and risk features?

2) How to identify high-level risks across Simultaneous Multi-Projects?

3) How can the relationship between objective and subjective variables be determined and their impact on measuring the level of risk?

After the introduction section, the reminder structure of this paper consists of the following: Section 2 presents background and literature review to explain the main concepts and principles of risk Assessment in a Simultaneous MultiProjects Development Environment. Section 3 displays the research experiment to answer the questions of the paper and explain the results. Finally, Section 4 consists of the conclusions extracted from research and future work representing expanded trends for current work.

\section{BACKGROUND AND LITERATURE REVIEW}

Many different studies have addressed risk management in software development projects. It has been subjected to various titles such as software development risks, software project risks, and IT projects risks. Some focus on completing a list of detailed points and risk points. Others include methods of analyzing and assessing levels of risks, including what deals with studies, statistical analysis, and methods of data mining.

Despite more than 30 years of extensive research into the analysis and management of the risks of software development projects, this has led to unified guidance on software project risk management. Adopting these risk management methods in practice still needs more attention so that software projects can be submitted in accordance with the required performance standards. Therefore, this still faces huge challenges [32].

There are six foundations for risk management. It includes risk management as modeling: rational process, factor analysis, capability, social process; and data analysis [5].

By studying more than 100 projects by [23] they found relationships between risk management practice and success in achieving projects in a timely and budgetary manner. They conclude that higher levels of risk management in project management achieve higher levels of project success [23]. 
In short, risk management is a critical success factor in the implementation of a successful project by identifying and eliminating project risk levels. Senior management supports risk management, the actual practice of risk management practices, and regular risk monitoring [35]. Therefore, the success of the project can occur more frequently [36].

The success of software projects is a subjective process that may vary from project to project and is linked to many risks. Project managers may differ because of these risks depending on the demographic characteristics of managers and the project's nature and features. This study attempted to identify and measure software risks' dimensions and analyze differences in perception among project managers about software risks [26].

Based on a research case study, de Packer and others concluded that risk management activities contribute to the project's success by creating a shared vision of the project with beneficial communication and direct effects [4].

The [17]study has shown a relationship between risk management, success, and self-performance of IT projects. Good risk management can lead to project success only if risks are identified and controlled before the project begins [17].

In a study conducted for measuring risk management impact on IT projects' success, researchers collected data from 200 IT project managers and used statistical analytical methods to measure this effect. The study found that there was a positive impact of risk management on IT projects' success [21].

High-tech and complex projects are more vulnerable to resource risks. Scope and resource risks are also vital risk categories for high-end, high-tech, and medium-complex projects [43].

According to [16] study, one of the complex challenges facing the multi-project environment is allocating resources between projects, especially if resources are minimal. Therefore, Project managers have to make resource allocation decisions to complete the project package in time or reduce project delays. Therefore, multi-project management is a growing area of research [16].

In a recent study, the researcher presented a viable model for monitoring software development projects in international companies. This solution is based on earned value management EVM and Monte Carlo as a simulation method. The proposed model in this study has provided proactive risk management that meets the project's objectives and adapts to changing resource needs [20].

The researchers presented a study on the analysis of risk assessment elements in a multi-project environment. Researchers used some Data Mining methods to reach the elements influencing risk assessment in the multi-project environment and suggested conducting further study and analysis on this topic [38].

\section{A. Risk in Software Development Projects}

According to the PMI definition, there are two levels for each project: individual Risks and overall risk. Individual risks can affect project objectives positively or negatively if they occur [22]. Risk refers to the factors that influence the project's success or failure. Also, agile principles include some of the principles to support risk management [18]:

1) Customer satisfaction has the highest priority through all phases of the project to deliver valuable software.

2) They welcome changing requirements until late in development, as agile's operations contribute to change in favor of customer's competitive advantage.

3) Developers and Businesspeople should work as a team throughout all phases of the project.

Previous principles and any best practice supporting applying those principles eliminate or mitigate the negative impact of risks (threats) or promote positive risks (opportunities) that often lead to project success, challenges, or failure [19].

Although one of the new development methodology goals, such as agile, is to reduce the harmful risks and maximize the positive opportunities for software projects' success. In contrast, three principles of agile mentioned in the previous paragraph prevent the occurrence of causes and causes that affect customer satisfaction and the quality of software products. But one of the researchers observed that the final elimination of risks is complicated. Still, there are clear differences between development software projects by a traditional methodology and projects with an agile methodology.

Fig. 2 displays a comparison of risk through the project between waterfall and agile projects. The figure illustrates that all projects have a risk regardless of the development methodology of the software project. Besides, the figure displays that agile projects have a declining risk model wherein agile projects risk declines as the project progresses, whereas in waterfall project has increased risk model. with agile project management, the days of catastrophic failure decline with the project's progress. The elimination of largescale failure is the biggest difference between risk on a waterfall and agile projects [33].

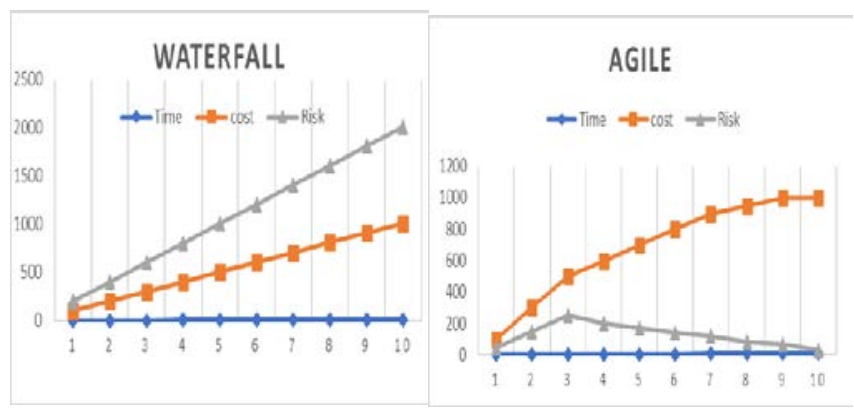

Fig. 2. (a) Comparison of Risk and Cost between Waterfall and Agile Projects (Adapted from [33]). 


\section{B. Risk Management in Simultaneous Multi-Projects Development Environment}

In most software companies, multiple software development projects are executing concurrently. The cause of existing projects is related to achieve the strategic goals of the enterprise. And there is a need to manage multiple projects together; therefore, critical success factors must be analyzed and worked in an isolated manner and an entire environment, including all parallel projects. Resource management is one of the most important aspects of a multi-project management environment because it requires a participatory vision that contributes to resource planning and coordination, allocation, and balance of projects [12].

Simultaneous projects share human and material resources, so project managers must consider the constraints imposed on each project and between projects to succeed. Risk management is addressed at all stages of the project and explicitly addresses scope, schedule, budget, and quality. In short, if resources are not managed perfectly, projects may face some challenges that could lead to project failure [39].

The author in [11] acknowledged that the comprehensive framework for risk management in multi-project environments (MPE) is still missing. This framework captures and manages the overall characteristics of MPE. The framework identifies adaptation variables that affect relationships and their risk outcomes and a core group of mediators and supervisors. [11] Risk management during the life cycle of the project has become more important and necessary. It is the best way to visualize project critical success factors entirely, support resource allocation decisions, and solve problems more efficiently. Therefore, academic researchers and industrial practitioners have still had more interest in studying risk management in recent years [39].

Multi-project management is currently a reality in software development environments. Continuous product changes or range levels characterize software development projects. The program development process is complex, particularly in human resources management, such as knowledge and technical expertise. These characteristics may be risk factors that need to be managed. Tactical management is therefore required to use information in an orderly manner, which leads us to consider using a metric-based strategy as a support tool for multiple project managers focusing on risk factors. The researchers, therefore, suggested applying the "risk points" scale and its diversity in the multi-software development project environment as a tool to support the decision and monitor risks during the project life cycle [3].

It is common for many companies to manage project risk separately and not to monitor and analyze the risk impact between projects across the organization. However, the prevailing situation is a simultaneous and shared project resource environment, so the main essence of the decisionmaking process is communication between partners involved in the organization's shared resources. Communication must be organized vertically and horizontally, and this is the meaning of participatory management [30].
Much of the literature ignores that the risks can be shared among different simultaneous development projects in the enterprise. At the same time, the risks in all levels of management and the relationships among risks are high. So, it would be appropriate to manage the risk from a holistic perspective. So, to better understand, consider the following toe levels of Risk Management [39]:

1) Risk management of one project: The enterprise has one project; the aim is to manage related risks to ensure the project's success.

2) Risk management of multiple projects: The enterprise has the risk management of a single project in addition to the common risks in the multiple projects' environment. So, the enterprise has a matrix of project risks. The aim is to ensure project success, system optimization, and the allocation of resources and analyze the impact of resource allocation on multiple projects.

The author in [10] illustrate those risks must be managed when managing multiple projects. With the organizational structure and the appropriate software, you can also share and monitor risks in all projects. At any time, the large organization implements different types of multiple projects at the same time. These projects have different sizes and stages of completion. In this environment, risk management can face a variety of challenges and bring significant benefits, some of which are [10]:

1) Cost savings by identifying overall risk mitigation.

2) Risk vision varied in multiple projects.

3) Reducing emergency budgets.

4) Effective distribution of resources.

\section{Assessing the Impact of Risks and Prioritizing Software Development Projects}

As shown in Fig. 3, assessing the impact of risks and prioritizing risks to be dealt with are outlined in the second and third steps of the risk management process. This assessment usually shows how cost or technical performance can affect the achievement of targets. However, the implications of these standards are not limited; It is also necessary to consider the political or economic consequences. The likelihood of any threat that may adversely or positively affect the project is also assessed. This assessment often involves the use of self-assessment techniques, especially if it is difficult to use objective methods to assess the possibilities directly. (i.e., engineering, analysis, modelling, and simulation) [8].

According to IEEE standard 729, a software requirement includes three types that display in Fig. 4:

Functional requirements: these are requirements that are requested by the end-user specifically standard should be provided by the system. Since non-functional requirements including scalability, security, maintainability, reliability, scalability, performance, reusability, and flexibility. Area requirements: area requirements are those of a particular category or area of the project [13]. Table I displays some software requirements standards and studies. 


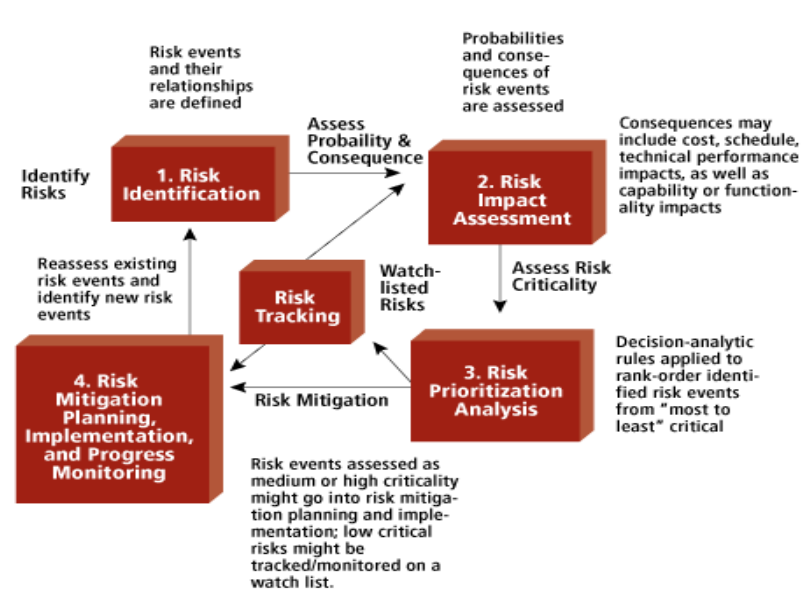

Fig. 3. The Fundamental Steps of Risk Management [8].

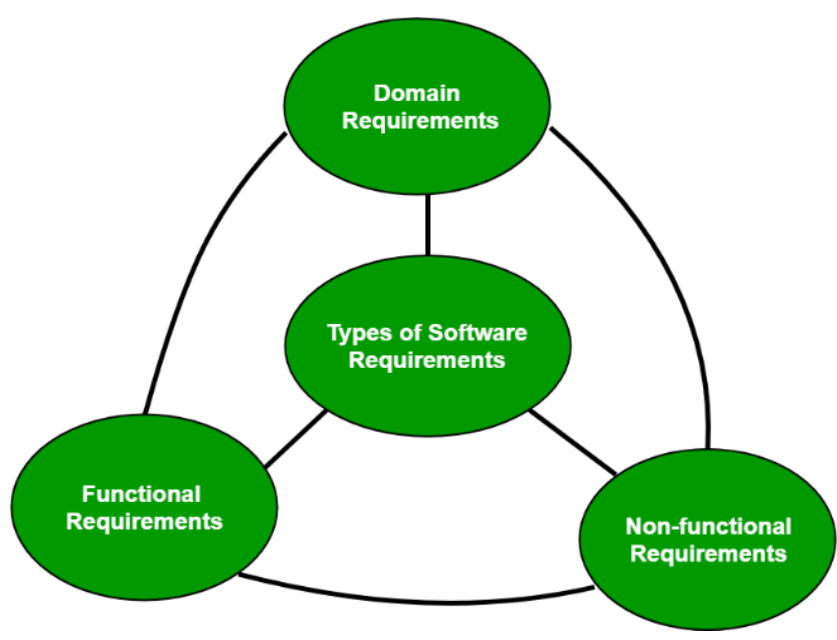

Fig. 4. Software Requirements [13].

TABLE I. SOFTWARE REQUIREMENTS

\begin{tabular}{|c|c|}
\hline Study/standard & Software Requirements \\
\hline $\begin{array}{l}\text { [45] } \\
\text { ISO/IEC } 9126\end{array}$ & $\begin{array}{l}\text { "Portability" has "co-existence", } \\
\text { "Maintainability", "Functionality", "Security”, } \\
\text { "Efficiency", "Reliability", "Usability", and } \\
\text { "Compatibility". }\end{array}$ \\
\hline $\begin{array}{l}{[44]} \\
\text { IEEE standard } 729\end{array}$ & $\begin{array}{l}\text { Functional Requirements, } \\
\text { Non-functional requirements (Flexibility, } \\
\text { Scalability, Reusability Portability, Reliability } \\
\text { Security, Performance Maintainability, and. } \\
\text { Domain requirements) }\end{array}$ \\
\hline [41] & $\begin{array}{l}\text { Functional requirements (FR), Operational } \\
\text { requirements (OR), Technical requirements } \\
\text { (TCR), and Transitional requirements (TSR) }\end{array}$ \\
\hline [27] & $\begin{array}{l}\text { Security, Interfaces, Functional, } \\
\text { Supportability, Usability, Standards, } \\
\text { Reliability \& Availability, Constraints, } \\
\text { Performance, Safety. }\end{array}$ \\
\hline $\begin{array}{l}\text { [15] } \\
\text { ISO/IEC/IEEE29148:2018 }\end{array}$ & $\begin{array}{l}\text { Business Requirements Specification (BRS), } \\
\text { System Operational Concept (OpsCon), } \\
\text { Stakeholder Requirements Specification } \\
\text { (StRS), Software Requirements Specification } \\
\text { (SRS) } \\
\text { System Requirements Specification (SyRS), }\end{array}$ \\
\hline
\end{tabular}

According to the study conducted by [1], he found that the most frequent software risks are planning and controlling user requirements, risks associated with the project team, risks related to the organizational environment, and project complexity [1]. Another previous study by [25] showed that the risks of the software project were interrelated. the risk dimensions include technology experience, project size, and project structure used in the system requirement, planning and control, project complexity, team, and organizational environment [25]. Table II displays some software risk dimensions studies.

TABLE II. SUMMARIZES SOME OF THE STUDIES ON SOFTWARE RISK DIMENSIONS

\begin{tabular}{|c|c|c|c|}
\hline Study & Year & No & Software Risks Dimensions \\
\hline$[40]$ & 1993 & 3 & $\begin{array}{l}\text { Development Environment Product Engineering } \\
\text { Program Constraints }\end{array}$ \\
\hline [28] & 1995 & 3 & Technical, Organizational, And Environmental, \\
\hline [9] & 2002 & 3 & $\begin{array}{l}\text { Management (Customer \& Stakeholders, } \\
\text { Corporate), Technology (Performance, } \\
\text { Application, Requirements) } \\
\text { External (Culture, Natural Environnent, } \\
\text { Economics), }\end{array}$ \\
\hline [34] & 2004 & 4 & $\begin{array}{l}\text { Requirements - User - Planning \& Control - } \\
\text { Project Complexity }\end{array}$ \\
\hline [1] & 2011 & 5 & $\begin{array}{l}\text { Organizational Environment, Team, Planning and } \\
\text { Control, User Requirements, and Project } \\
\text { Complexity }\end{array}$ \\
\hline [25] & 2011 & 9 & $\begin{array}{l}\text { Success Risk, External Risk, Financial Risk, } \\
\text { Technology Risk, Management Risk, Business } \\
\text { Processes Risk, Security Risk, People Risk, } \\
\text { Information Risk, And }\end{array}$ \\
\hline [7] & 2013 & 9 & $\begin{array}{l}\text { Organizational Environment, Project Size, } \\
\text { Planning, And Control, Team, Technology } \\
\text { Experience, Project Complexity, System } \\
\text { Requirement, Project Structure, User, }\end{array}$ \\
\hline [39] & 2013 & 11 & $\begin{array}{l}\text { Cost, Time, Quality, Team, Risk, Size, Changes, } \\
\text { Complexity, Design, Organizational }\end{array}$ \\
\hline [31] & 2014 & 6 & $\begin{array}{l}\text { Resource Risk, Technical Risk, Personnel Risk, } \\
\text { Legal Risk, Financial Risk, Management Risk, } \\
\text { Contractual and Other. }\end{array}$ \\
\hline [22] & 2017 & 4 & $\begin{array}{l}\text { External Risk- Technical Risk -Commercial Risk- } \\
\text { Management Risk- }\end{array}$ \\
\hline [27] & 2018 & 14 & $\begin{array}{l}\text { Schedule, Estimations, Organizational } \\
\text { Requirements, Requirements, Project Cost, } \\
\text { Complexity, User, Project Complexity, Software } \\
\text { Requirement., Team, Planning and Control, } \\
\text { Organizational Environment, }\end{array}$ \\
\hline
\end{tabular}

\section{Research Experiment}

In this part of the research, the aim is to answer research questions through the results that will be reached in this experiment. One of the data mining tools that will be used as a tool for data mining is Weka 3.8.4. Therefore, this section of the research is divided into five subsections:

1) Data set.

2) What are the relationships between Risk level and Risk Features?

3) How to Identify top risks across Simultaneous MultiProjects? 
4) Identify the association between the subjective and objective variables and their impact on measuring risk levels?

5) Overall comment on the search experience.

\section{E. Data Set}

In this study, the researchers used the data set in [27]. This data set includes 12 variables describing the risks of several projects for software development, some of which are project type, requirements, impact, probabilities, and priority risks where it is fully presented in Table III, The researcher based the challenge of the listed variables on several methods [27]:

1) Previous studies, especially studies [34].

2) The experts have at least five years of experience in the software industry companies that achieve the second and third levels in the maturity and ability model.

3) The number of cases in the dataset consists of 299 instances. the dataset is formatted in Attribute-Relation File Format (ARFF) [27].

\section{F. Answer to Question 1: What are the Relationships between Risk Level and Risk Features?}

The first question in this paper is the relationship among the risk characteristics and assess the risk levels. Determining this relationship is very important for identifying the traits with the most significant effect. Recognizing this relationship contributes to forming the risk record and risk dataset to help manage projects centrally because the appropriate vol ume of data is the target, neither more nor fewer. Collecting too much data represents a cost and effort lost and may distract the decision-maker and collecting too little data is insufficient.

Attribute reduction is an important area of research in machine learning, artificial intelligence, and pattern recognition to improve the performance and economics of predictions. Attribute reduction participates in identifying redundant attributes to remove this redundancy and improve decision-making [24]. So, attribute reduction represents an essential step in the preprocessor of data mining, machine learning tasks, and data pattern recognition [2].

Many factors affect the risk assessment of the software development project. These factors are divided into two types, subjective and objective. Factors that are objectively measured and objectively described are not affected by the personality of the person who counts them. In contrast, other variables describing project risk are subjective values, such as the impact, magnitude, likelihood of occurrence, and frequency of risk, and are influenced by the character of the decisionmaker.

The experiments that were conducted in this research where use many methods for feature selecting. Using more than one feature selection method confirms results to solve the feature's problem. The research seeks to identify the characteristics with the most significant impact from all methods. Also, The second sub-objective in this research is what the features don't relate to assessing the risk level based on many methods. Clarifying this issue is of great importance to decision-makers in designing the software company's risk register. The risk register is the appropriate tool for compiling project risk data, followed by analyzing these data to help the analysis results formulate proper strategies for efficiently managing software development risks. Table IV displays The results.

Six methods were used in the research experiment to determine which features are more important in risk assessment. The six methods then unanimously agreed on the importance of three features: priority, probability, risk size. Fig. 5 shows that although the relationship between the magnitude of the risk and the level of risk is substantial. In some cases, the relationship level may decrease due to other factors that may be requirements and impact, like what's shown in shape.

On the other hand, by the relationship thread, three methods confirmed no significant relationship between two features(Affecting No of Modules, Fix Cost (\% of the project), and the risk level assessment.

These features (Affecting No of Modules and Fix Cost) have nothing to do with a risk assessment, which does not mean they are unimportant. However, their importance still exists as necessary information in managing the risks of the software project and not in determining the level of risk.

TABLE III. The StRucture of DAta SET

\begin{tabular}{|c|c|}
\hline Attributes & Value Sets \\
\hline Requirements & Text to describe the requirements \\
\hline $\begin{array}{l}\text { Project } \\
\text { Category (PC.) }\end{array}$ & $\begin{array}{l}\text { 1. Transaction Processing System (TPS) } \\
\text { 2. Management Information System (MIS) } \\
\text { 3. Enterprise resources planning System (ERP) } \\
\text { 4. Safety-Critical System (SCS) }\end{array}$ \\
\hline $\begin{array}{l}\text { Requirement } \\
\text { Category(RC.) }\end{array}$ & $\begin{array}{l}\text { Reliability \& Availability-- Usability- Security- Safety - } \\
\text { Supportability - Functional - Constraints, Interfaces - } \\
\text { Standards- Performance }\end{array}$ \\
\hline $\begin{array}{l}\text { Risk Target } \\
\text { Category } \\
\text { (RTC) }\end{array}$ & $\begin{array}{l}\text { Budget - Personal -Resource Availability-Quality-Schedule } \\
\text {-Performance-Functional Validity-People -User- } \\
\text { Requirement - Dimension- Time - Cost Design- Project } \\
\text { complexity- Unrealistic Requirements Business - } \\
\text { Overdrawn Budget-Process - Software - Planning \& } \\
\text { Control - Team- Organizational Environment- }\end{array}$ \\
\hline Probability(Pro) & $0 \%-100 \%$ \\
\hline $\begin{array}{l}\text { Magnitude of } \\
\text { Risk(MoR) }\end{array}$ & $\begin{array}{l}\text { Extreme - Very High - High - Medium - Very Low - Low- } \\
\text { Negligible }\end{array}$ \\
\hline Impact(Imp) & Catastrophic, high - moderate- Low- insignificant \\
\hline $\begin{array}{l}\text { Risk } \\
\text { Dimensions } \\
\text { (RD.) }\end{array}$ & $\begin{array}{l}\text { Requirements- Estimations -Project complexity- planning } \\
\text { and control- Project cost - Team, Planning, and Control - } \\
\text { User - Organizational Environment- Software Requirement } \\
\text { - Schedule - Organizational Requirements - Complexity, }\end{array}$ \\
\hline $\begin{array}{l}\text { Affecting No } \\
\text { Modules(ANM) }\end{array}$ & Numbers of Modules \\
\hline $\begin{array}{l}\text { Fixing } \\
\text { Duration(FD) }\end{array}$ & Period by Day \\
\hline $\begin{array}{l}\text { Cost of } \\
\text { Fixing(CoF) }\end{array}$ & $\%$ project cost \\
\hline Priority(Pri) & $0 \%-100 \%$ \\
\hline Risk Level(RL) & $1-2-3-4-5$ \\
\hline
\end{tabular}


TABLE IV. THE RESUlt OF ATtRIBUte REDUCtION

\begin{tabular}{|c|c|}
\hline Relief F Attribute Eval & Info Gain Attribute Eval \\
\hline Ranked attributes: & Ranked attributes: \\
\hline 0.243344 Pro & 1.908511 Pri \\
\hline 0.2364811 Pri & 1.4744 Pro \\
\hline $0.213395 \mathrm{MoR}$ & $0.46055 \mathrm{MoR}$ \\
\hline $0.120291 \mathrm{PC}$ & 0.28923 RTC \\
\hline 0.074393 RTC & 0.197 7 DoR \\
\hline $0.053512 \mathrm{RC}$ & $0.19361 \mathrm{PC}$ \\
\hline $0.036737 \mathrm{DoR}$ & 0.12649 FD (Days) \\
\hline 0.020749 FD (Days) & 0.11452 RC \\
\hline 0.013748 ANoM & 0.04486 Impact \\
\hline 0.0028910 FC (\% of Project) & $08 \mathrm{ANoM}$ \\
\hline-0.001396 Impact & 010 FC (\% of Project) \\
\hline Correlation Attribute Eval & Gain Ratio Attribute Eval \\
\hline Ranked attributes: & Ranked attributes: \\
\hline 0.456311 Pri & 0.961111 Pri \\
\hline 0.45184 Pro & 0.61074 Pro \\
\hline $0.19645 \mathrm{MoR}$ & $0.19945 \mathrm{MoR}$ \\
\hline 0.17349 FD (Days) & 0.14079 FD (Days) \\
\hline $0.13281 \mathrm{PC}$ & $0.10341 \mathrm{PC}$ \\
\hline 0.118 ANoM & 0.07533 RTC \\
\hline 0.0783 RTC & $0.05867 \mathrm{DoR}$ \\
\hline 0.067210 FC (\% of Project) & $0.05352 \mathrm{RC}$ \\
\hline $0.06152 \mathrm{RC}$ & 0.02286 Impact \\
\hline $0.05227 \mathrm{DoR}$ & $08 \mathrm{ANoM}$ \\
\hline 0.04816 Impact & 010 FC (\% of Project) \\
\hline One R Attribute Eval & Symmetrical Uncert Attribute Eval \\
\hline Ranked attributes: & Ranked attributes: \\
\hline 98.66211 Pri & 0.963611 Pri \\
\hline 86.288 4 Pro & 0.67174 Pro \\
\hline $55.8535 \mathrm{MoR}$ & $0.21495 \mathrm{MoR}$ \\
\hline 46.154 8 ANoM & $0.10061 \mathrm{PC}$ \\
\hline 44.4826 Impact & 0.09943 RTC \\
\hline 44.1479 FD (Days) & 0.0889 FD (Days) \\
\hline $43.8132 \mathrm{RC}$ & $0.07387 \mathrm{DoR}$ \\
\hline 43.14410 FC (\% of Project) & $0.05572 \mathrm{RC}$ \\
\hline 43.144 7 DoR & 0.02276 Impact \\
\hline $42.8093 \mathrm{RTC}$ & $08 \mathrm{ANoM}$ \\
\hline $42.8091 \mathrm{PC}$ & 010 FC (\% of Project) \\
\hline
\end{tabular}

On the other hand, the other six characteristics: project category, risk target category, risk requirements, and risk dimensions, duration of determination (days), and impact on various centers impact risk assessment in software projects.

\section{Figure 5 : The relationship between Magnitude of Risk and Risk leve}

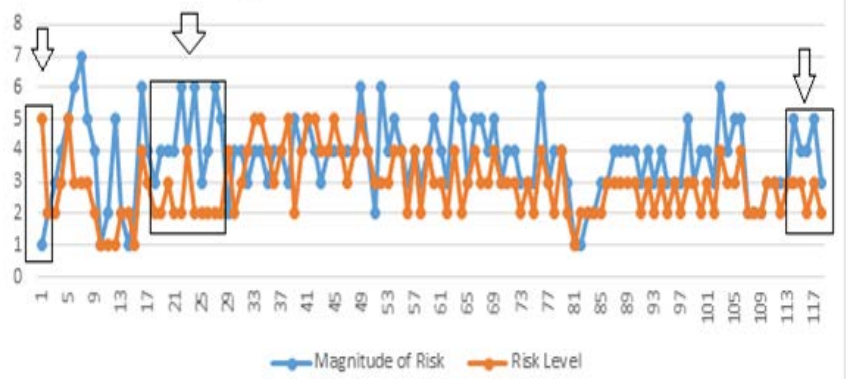

Fig. 5. The Relationship between the Magnitude of Risk and Risk Level.

\section{G. The Answer of Question 2: How to Identify Top Risks Across Simultaneous Multi-Projects?}

The systemic risk is the risk that often occurs throughout the organization. The treatment of risk is better to deal with when using a centralized database, although the project manager tries to search through many different project risk records in spreadsheets. Because these risks are in a multiproject environment, the project manager may be allowed to focus on his project. However, preparing the emergency budget for systemic risks is the responsibility of the program manager. Central risk management is a better methodology for reducing overall risk costs [10].

Identifying the "top 10" risks across multiple projects is a common requirement to monitor the most critical risks based on Central risk management methodology. It requires each project manager to provide information on the most significant risks to their project. However, this may lead to an error assessment of risk, as the fourth risk in one project may be more influential than the second risk in another. This situation does not mean the wrong risk assessment only but also may lead to the concealment of a great deal of potential impact, as shown in Fig. 5 [10].

The project results for the project differ from the risk data analysis for simultaneous enterprise-wide projects. Some managers may extract the results of a single project on its scale and then combine the results of project risk analysis in a single scenario [10]. This approach may face some criticism when dealing with this problem such as:

1) It is not commensurate with the dynamic nature and management of projects.

2) It may lack integrated centralized management to achieve a unified enterprise-wide vision.

Therefore, the art of research focuses on the central management of all project data together.

The graphic forms illustrate this Fig. 6 representing a static image at a particular moment in the life of the simultaneous development environment for the four projects included in the data upon which the research relied. The state 
of the risks with the highest priority may differ from the view of Collective centralization from individual mono view at the level of a single project. The development of software in the environment of software companies does not take place in isolated islands; but instead, there is a sharing of resources and goals.

Fig. 7 shows the relationship between some subjective measures of risk and the level of risk. Self-assessment traits are affected by a person's assessment, such as the probability and magnitude of the risk. The figure shows that in some cases, as shown in the form, the estimated value is that the risk is high, while at the company level, this risk is at a lower level than other risks to projects that coincide with the same project.

The unique view of the project manager who focuses on a single project may differ, as shown in Fig. 7, from the holistic view, which deals with multiple simultaneous projects as explained in previous Fig. 6. Fig. 7 focuses on Transaction Processing System Projects, where it deals with it independently and then seeks to deal with the most significant threat affecting the project level and allocates resources to it that contribute to its treatment. This evaluation is a minor view because it is not the only project in the organization. After all, there may be a risk associated with another project with a more significant impact on the organization level. If it is not addressed and allocated resources, it may cause more harm to the software company's reputation.

The overall view of simultaneous projects contributes to formulating a unified picture of project risks at the enterprise level. Integrated risk management brings many benefits based on addressing threats that significantly impact the entire company for cost savings. It also delivers competitive advantages, enhances opportunities to achieve strategic and operational objectives, thereby reaping the greatest benefits and improving operational efficiency.

By conducting a comparative analysis of the classification of risk levels in a multi-project environment using the following four methods. Table $\mathrm{V}$ presents the results of the comparison process, showing the levels of accuracy achieved:

1) Random Forest

2) REP Tree

3) Trees J48

4) Simple Logistic.

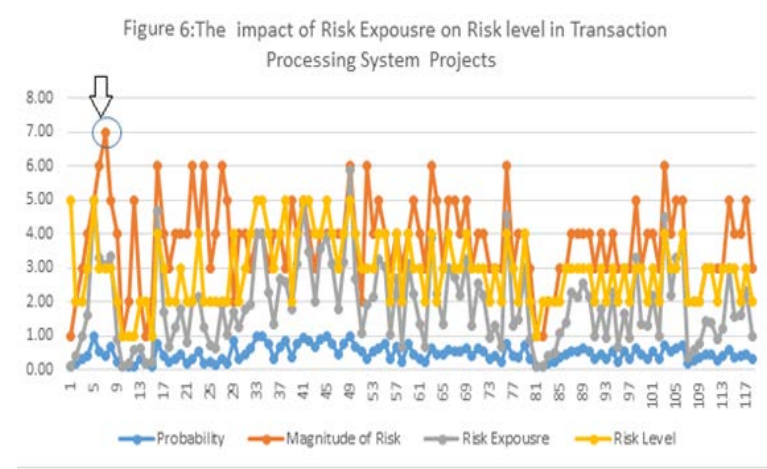

Fig. 6. The Impact of Risk Exposure on Risk Level in Transaction Processing System Projects(Concurrent).

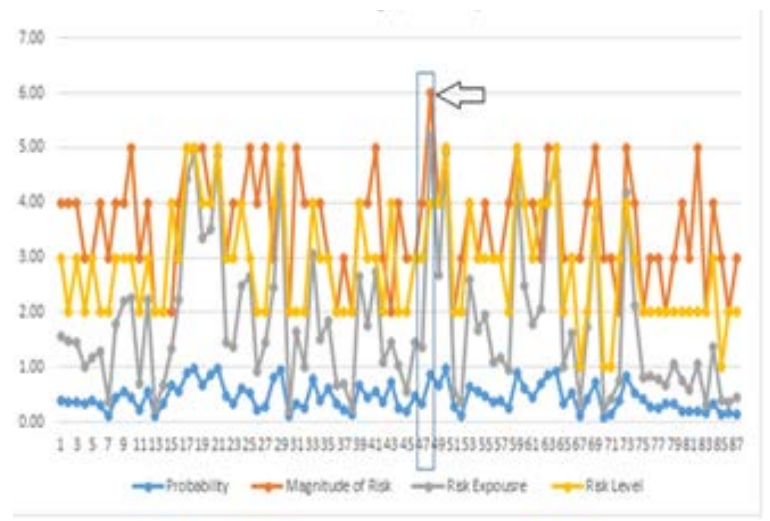

Fig. 7. The Impact of Risk Exposure on Risk Level in Transaction Processing System Projects.

TABLE V. SIMPLE LOGISTIC: CLASSES

\begin{tabular}{|c|}
\hline Class 1: \\
\hline $\begin{array}{l}207.79+ \\
{[\mathrm{RTC}=\text { Quality }] * 1.28+} \\
{[\mathrm{MoR}=\text { Negligible }] * 0.44+} \\
{\left[\text { Pri }{ }^{*}-10.07\right.}\end{array}$ \\
\hline Class 2: \\
\hline $\begin{array}{l}21.72+ \\
{[\mathrm{RTC}=\text { User }] *-1.09+} \\
{\left[\text { Pro }{ }^{*}-0.05+\right.} \\
{[\mathrm{MoR}=\mathrm{Low}]^{*} 0.64+} \\
{\left[\mathrm{MoR}=\text { High }{ }^{*} 1.05+\right.} \\
{\left[\text { Impact=Low }{ }^{*}-0.57+\right.} \\
{[\text { Pri }]^{*}-0.51}\end{array}$ \\
\hline Class 3: \\
\hline 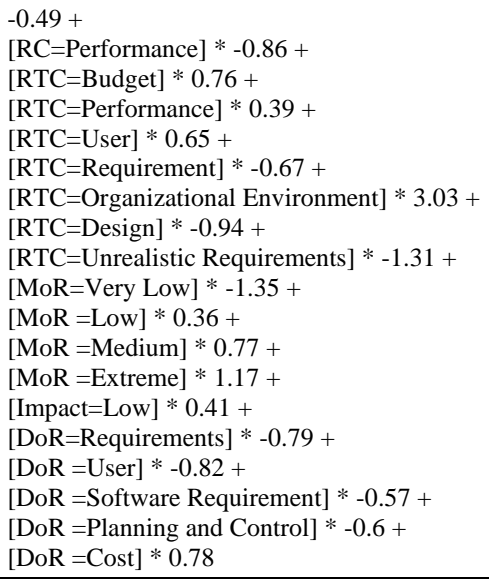 \\
\hline Class 4: \\
\hline $\begin{array}{l}-28.32+ \\
{[\mathrm{RC}=\text { Constraints }] *-0.72+} \\
{\left[\mathrm{RTC}=\text { Performance }{ }^{*}-0.64+\right.} \\
{[\mathrm{RTC}=\text { Functional Validity }] * 0.88+} \\
{\left[\text { Pro }{ }^{*} 0.04+\right.} \\
{[\mathrm{MoR}=\text { Medium }] * 0.65+} \\
{[\text { Impact=insignificant }] *-1.14+} \\
{[\mathrm{FD}(\text { Days })]^{*} 0.11+} \\
{[\text { Pri }] * 0.42}\end{array}$ \\
\hline Class 5: \\
\hline $\begin{array}{l}-154.64+ \\
{[\mathrm{RC}=\text { Security }] *-1.69+} \\
{\left[\mathrm{RC}=\text { Constraints }{ }^{*} 1.34+\right.} \\
{[\mathrm{RTC}=\text { FunctionalValidity }] *-1.69+} \\
{\left[\text { Impact=Low }{ }^{*}-3+\right.} \\
{[\text { Pri }] * 2.04}\end{array}$ \\
\hline
\end{tabular}


There are many ways to classify risk levels in individual and multiple enterprise environments as shown in Table V. Initially, kappa's statistical value is between 0.9034 and 0.9713, and Kappa is used to test the reliability between the rate of the model. Classification methods have an almost degree of accuracy, with accuracy coming from 93\% using a simple logistics method to approximately $98 \%$ using the REP tree. While error metrics are at very low levels, ranging from 0.0371 to 0.0126 , to measure the absolute average error (MAE) and to measure the proximity of final results to projections and the value of 0.1488 to 0.0888 for the average root square error scale (RMSE). RMSE represents the standard deviation of differences between expected values and observed values.

Table V cells display a forecast model to predict risk levels according to a simple logistical method. Each of the five cells describes the characteristics of each category of risk levels from level 1 to level 5.the extract results from Wika 3.8.4.

After review, the simple logistical forecast model achieved the lowest level of accuracy among the classification methods used in the experiment. The best predictive models were the two methods of forecasting (J48 and REP Tree) in the experiment of this research by displaying the classification decision tree in these two ways. J48 algorithm deals with noise, Not much affected by lost data, and deals with continuous features. See Fig. 8, 9,10, and 11.

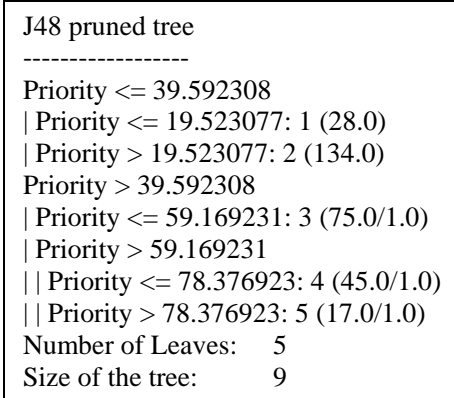

Fig. 8. J48 Pruned Tree.

Authors extract from the decision tree in the two methods; see Fig. 9,10 and 11. The main feature in the risk level classification is the priority, with rating values varying between evaluation methods. The risk priority feature represents a personal judgment of the project manager, who, according to the characteristics of each risk, determines the risk priority among the risks of simultaneous projects run by the company. In this regard, the experience and skills of project managers are critical to risk management in a multiproject environment. Therefore This requires a more in-depth and detailed study.

According to [42], J48 and REP Tree produce high classification and simple tree structure. The Reduced Error Pruning (REP) Tree in Fig. 10 and 11 show that the main factor for risk assessment is the priority of risk, which is the same result reached using the J48 tree displayed in Fig. 9, but there are some differences in digital values.

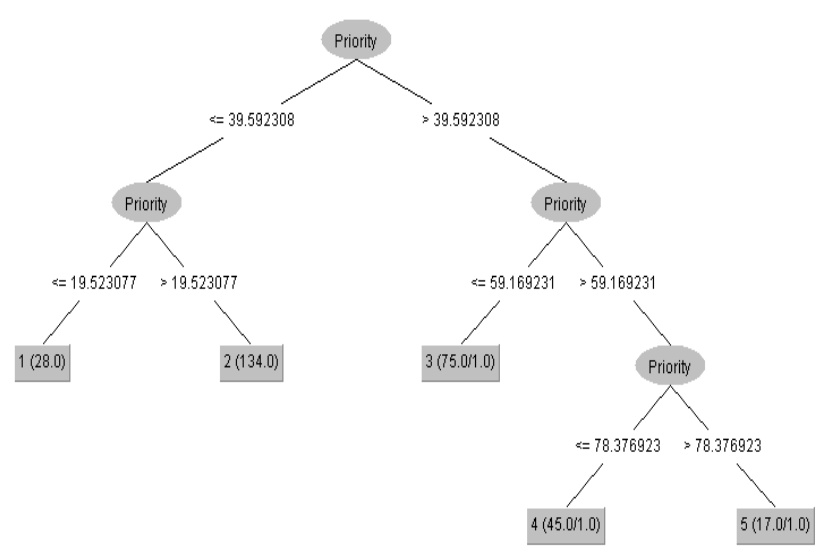

Fig. 9. J48 Tree of Classification.

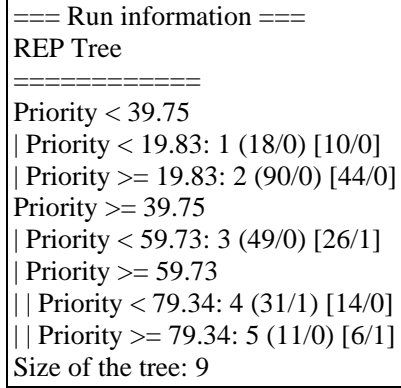

Size of the tree: 9

Fig. 10. REP Tree.

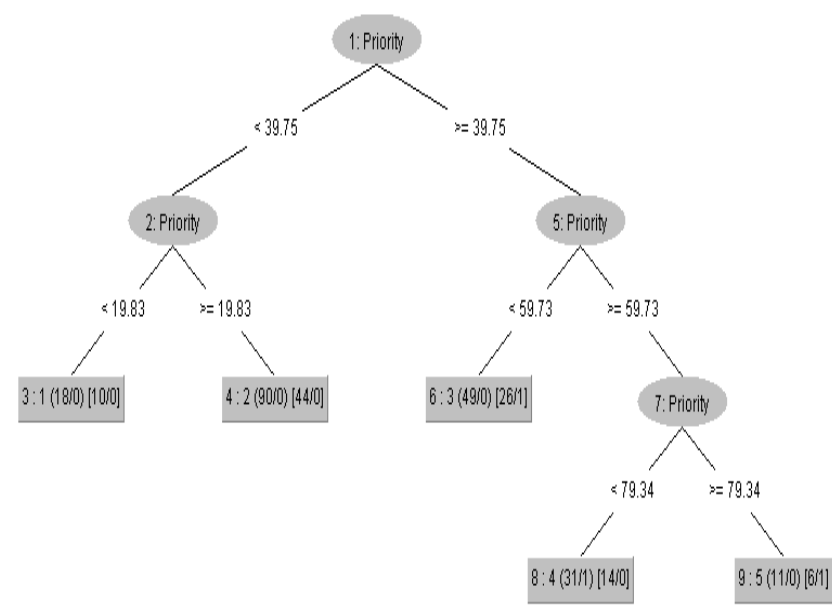

Fig. 11. REP Tree Structure Graph.

\section{H. The Answer of Question 3: Identify the Association} between the Objective and Subjective Variables and their Effect on Measuring the Level of Risk?

It is important to analyze the relationship between subjective and objective variables in assessing the risks of software development projects. Table VI shows the degree of correlation between these variables according to the data available at this research stage. It is noted from the results of the relationship analysis that there is a strong correlation between Priority, 'Risk Level', and Probability. At the same time, there is a weak correlation between 'Fixing Duration (Days), and others. 
TABLE VI. PEARSON'S CORRELATIONS

\begin{tabular}{|c|c|c|c|c|c|c|}
\hline $\begin{array}{l}\frac{0}{0} \\
\frac{\pi}{\pi} \\
\frac{\pi}{7}\end{array}$ & & 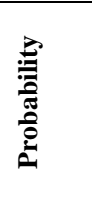 & 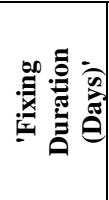 & 串 & 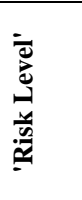 & 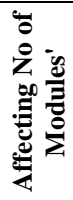 \\
\hline \multirow{2}{*}{$\begin{array}{l}1 . \\
\text { Probability }\end{array}$} & Pearson's r & - & & & & \\
\hline & p-value & - & & & & \\
\hline \multirow{2}{*}{$\begin{array}{l}\text { 2. 'Fixing } \\
\text { Duration } \\
\text { (Days)' }\end{array}$} & Pearson's r & 0.301 & - & & & \\
\hline & p-value & $<.001$ & - & & & \\
\hline \multirow{2}{*}{ 3. Priority } & Pearson's r & 0.962 & 0.367 & - & & \\
\hline & p-value & $<.001$ & $<.001$ & - & & \\
\hline \multirow{2}{*}{$\begin{array}{l}\text { 4. 'Risk } \\
\text { Level' }\end{array}$} & Pearson's r & 0.923 & 0.356 & 0.958 & 一 & \\
\hline & p-value & $<.001$ & $<.001$ & $<.001$ & 一 & \\
\hline \multirow{2}{*}{$\begin{array}{l}\text { 5. Afftecting } \\
\text { No of } \\
\text { Modules' }\end{array}$} & Pearson's r & 0.116 & 0.127 & 0.229 & 0.229 & \\
\hline & p-value & 0.046 & 0.028 & $<.001$ & $<.001$ & \\
\hline
\end{tabular}

I. Overall Comment on the Search Experience

It is clear from the research experience generally that the usual environment in software companies is a multi-project environment at the same time. Therefore, it requires an integrated management methodology to manage the risks of these projects together to achieve the company's general goals and then maintain its competitive capabilities and preserve its market share. This management methodology should include quantitative methods that help collect, analyze, and measure risk levels individually at the level of one project and collectively at the level of several projects that are developed simultaneously.

Project managers should also use data mining methods and statistical analysis techniques to reach knowledge levels that help allocate resources more efficiently. They must also use visual data presentation methods to determine the strengths and weaknesses that help them achieve critical success factors for software projects.

\section{CONCLUSION AND FUTURE WORKS}

At the end of this work, the following paragraphs summarize the findings of the results obtained and present some trends that need further study and analysis.

\section{A. Conclusion}

The central management of synchronous software projects gives a clear, integrated picture of the risk levels at the enterprise level. Data mining methods help identify the most important characteristics that must be recorded in the risk records of the enterprise database, where the study showed that the 12 characteristics included in the research data are important. This study has concluded with several important points, the most important of which are the following:

1) Priority, Probability, and Magnitude of Risk represent the main features to classify risk levels, where the six feature reduction methods in experimental ensure that.

2) The central unified risk vision of multiple simultaneous projects gives management an integrated picture to help it allocate resources in a more efficient way that contributes to the company's overall objectives.

3) The classification methods (Simple Logistics, REP tree, trees. J48, and Random Forest) used in the research experiment contributed to high results of reliability and accuracy reached $98 \%$ and low levels of classification error measures.

4) The priority of risk is the most important factor in classification according to the best methods in the research experiment, with different percentages.

a) Relying on an integrated management methodology for risk management in a concurrent project environment helps identify the most influential risks at the company level rather than at the individual project level. Therefore, This contributes to the more efficient allocation of resources to achieve the company's overall objectives.

\section{B. Future Work}

The following points represent some of the proposed future trends for research and study in this area:

1) Conduct a more in-depth analysis of the relationship between subjective and objective variables considering the reciprocated impact on risk measurement.

2) Risk level analysis in light of multiple software development methodologies.

3) Measure the level of individual and group experiences of the project managers in measuring risk levels.

4) Analyze and study the relationship between risk characteristics in a multi-project environment and company characteristics such as size, age, organizational structure, etc.

5) Identify a model to measure the impact of knowledge Management on Risk Management in software development companies.

6) What are the impacts of Blockchain technology on concurrent project management in an overseas company? Does it reduce the risks, support fixing Mistakes, to allocate resources efficiently?

\section{REFERENCES}

[1] Arnuphaptrairong, T.,2011, Top Ten Lists of Software Project Risks: Evidence from the Literature Survey. Proceedings of the International MultiConference of Engineers and Computer Scientists, 1. Hong Kong.

[2] Bai, J., Xia, K., Lin, Y., \& Wu, P, 2017, Attribute Reduction Based on Consistent Covering Rough Set and Its Application, Hindawi Complexity Volume 2017, Article ID 8986917, 9 pages.

[3] Jr, J., Wanderley M., Gusmão C. \& Moura H., 2016, Application of Metrics for Risk Management in Environment of Multiple Software Development Projects. In Proceedings of the 18th International Conference on Enterprise Information Systems - Volume 1: ICEIS, ISBN 978-989-758-187-8, pages 504-511. DOI: 10.5220/0005859 705040511.

[4] De Bakker, K. d., Boonstra, A., \& Wortmann H.,2010, Does risk management contribute to IT project success? A meta-analysis of empirical evidence, International Journal of Project Management 28 (2010) 493-503.

[5] Bannerman, P. L. (2015). A reassessment of risk management in software projects. In: Handbook on Project Management and scheduling, vol. 2 (pp. 1119-1134). Springer International Publishing.

[6] Barafort, B., Mesquida, A., \& Mas A.,2019 "ISO 31000-based integrated risk management process assessment model for IT organizations", Journal of Software: Evolution and Process, 2019. 
[7] Chawan, P. M., Patil, J., \& Naik, R.,2013. Software Risk Management. International Journal of Advances in Engineering Sciences, 3(1), 17-21.

[8] Garvey, P.R., 2008, Analytical Methods for Risk Management: A Systems Engineering Perspective, Chapman-Hall/CRC Press, Taylor \& Francis Group (UK), Boca Raton, London, New York, ISBN: 1584886374.

[9] Hall, D.C., \& Hulett D.T. 2002. Universal Risk Project-Final report. Available from the PMI Risk SIG website www.risksig.com, or www.techriskmgt.com/home2link.html.

[10] Han, Wen-Ming, \& Huang S.,2006. "An empirical analysis of risk components and performance on software projects." The Journal of Systems and Software, 2006: 42-50.

[11] Hashim, N.I., Chileshe, N., and Baroudi, B.,2012, 'Management challenges within multiple project environments: Lessons for developing countries, Australasian Journal of Construction Economics and Building, Conference Series, 1 (2) 21-31.

[12] Hopkins, R., Campbell, K., O'Reilly, D., Tarride, J., Bowen, J., Blackhouse, G., \& Goerre, R.. (2007). Managing Multiple Projects: A Literature Review of Setting Priorities and a Pilot Survey of Healthcare Researchers in an Academic Setting. Perspectives in health information management / AHIMA, American Health Information Management Association. 4. 4.

[13] Geeksforgeeks.org,2020, https://www.geeksforgeeks.org/softwareengineering-classification-of-software-requirements/ visited on 1/7/2020

[14] ISO 31000, 2018. ISO 31000:2018. Risk management - Principles and Guidelines, Risk Management. https://www.iso.org/standard/ 65694.html.

[15] ISO/IEC/IEEE29148:2018, https://www.reqview.com/doc/iso-iec-ieee29148-templates, visited on 1/7/2020.

[16] Klevanskiy, N.N., Tkachev, S.I., \& Voloshchouk, L.A.,2019, Multiproject Scheduling: Multicriteria Time-cost Trade-off Problem, Procedia Computer Science, Volume 150, 2019, Pages 237-243.

[17] Kornelius Irfandhi, 2016, Risk Management In Information Technology Project: An Empirical Study, ComTech Vol. 7 No. 3 September 2016: 191-199.

[18] Layton, M. C.,2020, Retrieved from What's Different about Agile Risk Management? https://www.dummies.com/careers/project-management/ whats-different-agile-risk-management/ 2020, 711.

[19] Li, Xiaoqing, Q., Hsu, M. K., \& Chen, Q.,2019, Support or Risk? Software Project, Risk Assessment Model, Based on Rough Set Theory and Backpropagation Neural Network, Sustainability 2019, 11, 4513; doi:10.3390/su11174513, https://www.mdpi.com/journal/sustainability.

[20] Marchwicka, Ewa.,2020, A technique for supporting decision process of global software project monitoring and rescheduling based on risk analysis, Journal of Decision Systems, DOI: 10.1080/12460125.2020. 1790825.

[21] Pimchangthong, D., \& Boonjing, V., 2017. Effects of risk management practices on IT project success. Manag. Prod. Eng. Rev. 8, 30-37. https://doi.org/ 10.1515/mper-2017-0004.

[22] PMI, Project Management Institute, 2017., A Guide to the PROJECT MANAGEMENT BODY OF KNOWLEDGE, Project Management Institute, Inc., Newtown Square, Pennsylvania 19073-3299 USA, p397.

[23] Raz, T.; Shenhar, A. J., \& Dvir, D.,2002, Risk management, project success, and technological uncertainty. R\&D Manag 32:101-109.

[24] Rong, W.,\& Ruixia, Y., 2017, "An algorithm for attribute reduction based on classification of condition attributes in rough set," 2017 29th Chinese Control And Decision Conference (CCDC), Chongqing, 2017, pp. 5534-5537, DOI: 10.1109/CCDC.2017.7979480.

[25] Sarigiannidis, L., \& Chatzoglou, P. D., 2011, Software Development Project Risk Management: A New Conceptual Framework. Journal of Software Engineering and Applications, 4(5), 293- 305.

[26] Sharma, A., Sengupta, S., \& Gupta, A.,2011, Exploring Risk Dimensions in the Indian Software Industry, Project Management Journal, Vol. 42, No. 5, 78-91.

[27] Shaukat Z., Naseem, R., \& Zubair, M., 2018, A Dataset for Software Requirements Risk Prediction, 2018 IEEE International Conference on Computational Science and Engineering, IEEE computer society pp112118.
[28] Sherer, S. A., 1995, "The three dimensions of software risk: technical, organizational, and environmental," Proceedings of the Twenty-Eighth Annual Hawaii International Conference on System Sciences, Wailea, HI, USA, 1995, pp. 369-378 vol.3, DOI: 10.1109/HICSS.1995.375618.

[29] Shortreed, J., 2010, “Enterprise Risk Management and ISO 31000”, The Journal of Policy Engagement, vol.2, no.3, 2010.

[30] Tabunshchyk, G., Arras, P., \& Merode, D. V., 2015, Risk Management in Multi-National Projects, 2015, The 8th IEEE International Conference on Intelligent Data Acquisition and Advanced Computing Systems: Technology and Applications 24-26 September 2015, Warsaw, Poland.

[31] Talet, A. N., Mat-Zin, R., \& Houari, M.,2014, Risk Management and Information Technology Project. International Journal of Digital Information and Wireless Communications, 4(1), 1- 9.

[32] Taylor, H., Artman, E., and Woelfer, J., 2012, Information technology project risk management: Bridging the gap between research and practice Journal of Information Technology 27(1):17-34 • March 2012.

[33] Vitalitychicago,2020, https://vitalitychicago.com/blog/agile-projectsare-more-successful-traditional-projects/ visited on 1/7/2020.

[34] Wallace, L. \& Keil, M. 2004, "Software Project Risk and their Effect on Outcomes", Communication fo the ACM, vol 47 number 4, pp. 68-73, 2004.

[35] Willumsen, P.; Oehmen, J.; Stingl, V.; Geraldi, J., 2019 "Value creation through project risk management", International Journal of Project Management, 2019.

[36] Zwikael O., \& Mark A.,2011 The Effectiveness of Risk ManagementAn Analysis of Project Risk Planning Across Industries and Countries, Risk Analysis Volume 31 issue 12011.

[37] Murta, Daniel \& Oliveira, José Nuno,2015, A study of risk-aware program transformation, Science of Computer Programming, Volume 110, Pages 51-77.

[38] Alharbi, Ibraheem M; Alyoubi, Adel A; Altuwairiqi, Majid; and Abd Ellatif, Mahmoud, " Analysis of Risks Assessment in Multi Software Projects Development Environment using Classification Techniques", accepted for publication in Advanced Machine Learning Technologies and Applications (AMLTA 2021), Series of Advances in Intelligent Systems and Computing, Springer, 2021.

[39] Júlio Menezes Jr; Cristine Gusmão; Hermano Moura, 2013, Defining Indicators for Risk Assessment in Software Development Projects, Clei Electronic Journal, Volume 16, Number 1, April 2013.

[40] Carr, Marvin., Konda, Suresh., Monarch, Ira., Walker, Clay., \& Ulrich, F.. (1993). Taxonomy-Based Risk Identification (CMU/SEI-93-TR-006 ). Retrieved February 20, 2021, from the Software Engineering Institute, Carnegie Mellon University website: http://resources.sei.cmu.edu/ library/asset-view.cfm?AssetID=11847.

[41] Pandey, Dhirendra; Suman, Ugrasen; and Ramani, AK, 2011, A Framework for Modelling Software Requirements, IJCSI International Journal of Computer Science Issues, Vol. 8, Issue 3, No. 1, May 2011, www.IJCSI.org.

[42] WNHW Mohamed, Mohd Najib Mohd Salleh, Abdul Halim Omar , A Comparative Study of Reduced Error Pruning Method in Decision Tree Algorithms, 2012 IEEE International Conference on Control System, Computing and Engineering, 23 - 25 Nov. 2012, Penang, Malaysia.

[43] Anjali Shishodia, Vijaya Dixit, Priyanka Verma, (2018) "Project risk analysis based on project characteristics", Benchmarking: An International Journal, Vol. 25 Issue: 3, pp.893-918, https://doi.org/ 10.1108/BIJ-06-2017-0151.

[44] IEEE Standard Glossary of Software Engineering Terminology," in ANSI/ IEEE Std 729-1983 , vol., no., pp.1-40, 18 Feb. 1983, doi: 10.1109/IEEESTD.1983.7435207.

[45] Desharnais, J.-M., Abran, A., \& Suryn, W. (2010). Identification and analysis of attributes and base measures within ISO 9126. Software Quality Journal, 19(2), 447-460. doi:10.1007/s11219-010-9124-5. 